\title{
Determinants of Delays in Health Care Utilization for Malaria Treatment (HCUMT) in Children under Five in Benin Southern Setting
}

\author{
Moussiliou N. Paraïso ${ }^{1}$, Alphonse Kpozèhouen², Yolaine Glèlè Ahanhanzo ${ }^{2, *}$, \\ Camara Facely ${ }^{2}$, Charles Sossa-Jerome ${ }^{1}$, Achille Massougbodji ${ }^{3}$ \\ ${ }^{1}$ Department of Health Promotion, Public Health Regional Institute, Benin \\ ${ }^{2}$ Department of Epidemiology and Biostatistics, Public Health Regional Institute, Benin \\ ${ }^{3}$ Department of Medicine and Specialities, Faculty of Health Sciences, University of Abomey-Calavi, Benin
}

Copyright $\bigcirc 2019$ by authors, all rights reserved. Authors agree that this article remains permanently open access under the terms of the Creative Commons Attribution License 4.0 International License

\begin{abstract}
Untreated or poorly treated malaria case is reported to progress to the severe form over time. Studies showed a high prevalence of untimely utilization of health service in low-income countries. The objective was to identify the determinants of late use of malaria treatment in children under five years of age in Ouidah, Benin. The study was cross-sectional and carried out during June 2017. Data on sociodemographic characteristics and malaria management were collected in randomly selected 450 couple mother-child pairs using a questionnaire. A multivariate analysis using a logistic regression and the stepwise digressive method was used to identify the determinants of late use of malaria treatment in children under five years of age. The prevalence of delayed utilization of health facilities for malaria management in children under 5 years was 87.8\% (95\% CI: 81.6\% - 92.8). Delays in health care utilization depended on whether mothers were married (OR $=4.4$, 95\% CI: 2.2-8.8), they used the motorcycle as a means of travel to health facilities $(\mathrm{OR}=2.3,95 \%$ CI: 1.1-5.2), complained about the high cost of transport (OR $=2.4,95 \% \mathrm{CI} 1.2-4.7$ ), or believed in the possibility of preventing malaria $(\mathrm{OR}=2.4,95 \% \mathrm{CI}$ : 1.2 - 4.7). When health care costs are paid by both the parents or by grandparents at the same time, then children were less likely to experience a delay $(\mathrm{OR}=0.4,95 \% \mathrm{CI}$ : 0.2 - 0.7). The prevalence of delays in health care utilization for malaria treatment (HCUMT) in children under five years is high in Ouidah in Benin south setting. Organization of simple malaria management through community training, regular and continuous supply of inputs (medicines and diagnostic tests) for malaria control would reduce the delays in HCUMT in children in Ouidah, Benin.
\end{abstract}

Keywords Malaria, Children, Health Care Utilization

\section{Introduction}

Malaria is still a major public health concern. In Benin, 680785 cases of malaria have been reported in children under five representing $42.5 \%$ of the burden of disease in all age groups, and $44 \%$ of malaria-related morbidity among the under-fives in 2015 [1]. Severe malaria is the main cause of death in hospitals, $20.8 \%$ of deaths in the general population and 38\% in children under five [1-4].

The last mid-term evaluation of the National Strategic Plan (2015-2018) implemented by Benin National Program against Malaria revealed the strengths and weaknesses of malaria control at both the implementation and effectiveness levels [5, 6]. The number of deaths caused by malaria remains high despite the efforts made in the past years. The large gap between expected (105 deaths) and the number of deaths recorded in 2015 (1747 deaths) shows that more efforts still have to be made. The proportion of timely treatment of malaria in children was $24 \%$ in Benin, while this proportion is even lower (23\%) in the department of Atlantic.

The incidence of severe malaria (26.7\%) and its lethality $(0.6 \%)$ are high in Atlantic department [7]. In this area, the strategy of community malaria management is not yet implemented unlike most health zones in Benin. However, there are functional community health workers. They are not trained in the community-based management of malaria, and their non-involvement in health care represents a missed opportunity.

An untreated or poorly treated malaria case is reported to progress to the severe form over the passage of time. This process may lead to an increase in the number of cases of severe malaria in areas where seeking care in health facilities is low. Delay in health care utilization would be a major obstacle to effective malaria control and several studies in sub-Saharan Africa have shown a high 
prevalence of untimely utilization of health service. Determinants for this situation are grouped into five groups: factors related to health facilities; factors related to mothers; factors related to the child; factors related to the social environment; and factors related to the disease [8-13]. The objective was to investigate the determinants of late use of malaria treatment in children under five years of age in Ouidah commune in Benin.

\section{Materials and Methods}

\subsection{Setting}

The Town of Ouidah is located in Atlantic department, $40 \mathrm{~km}$ from Cotonou, the economic capital. It covers an area of $364 \mathrm{~km}^{2}$ with sixty (60) outskirts and villages. Its population was estimated at 185,938 inhabitants in January 2017 with a proportion of children less than five years of age about $18.0 \%$. The health system includes 10 Health facilities (CSA) that provide care against malaria and 01 district Hospital. Malaria transmission occurs throughout the year. Health human resources ratio is 01 physician per 10000 inhabitants, 1.24 nurses per 5000 inhabitants, and 2.45 midwives per 5000 inhabitants [7].

\subsection{Study Design and Sampling}

The study was cross-sectional. It was conducted during June 2017 and had concerned two targets: children under five years of age with fever during the two weeks preceding the survey and the mother or caretaker of the same child who had lived in the commune for at least six months. The respondents were selected by a probabilistic method using a two-stage sampling technique. The minimum size of the sample was estimated at 450 couple mother-child pairs.

\subsection{Variables and Measurements}

The dependent variable was the delay in health care utilization for malaria treatment (HCUMT) in children. A delay was considered when the time between the onset of the fever and the utilization of health care facility for treatment was over $24 \mathrm{H}$.

The independent variables were: i) the sociodemographic characteristics of the children and their mother; ii) the knowledge of malaria, their perception of the care system and malaria, their behavior towards malaria; ii) the social environment of mothers or caregivers; and iv) the disease characteristics (fever, mode of onset, associated manifestations).

The level of knowledge of mothers on malaria was assessed based on five domains: cause; mode of malaria transmission; manifestations; treatment; and prevention. Each of the areas was assigned a score of three. The total score was obtained by the sum of the partial scores of the five domains and was rated low if it was lower or equal to 5 , if it was between 6 and 10 it was considered good, and high when it was between 11 and 15 .

\subsection{Data Collection and Analysis}

Data were collected using a questionnaire pre-tested in a neighboring health center of the same Department of the Atlantic. Five collectors carried out the collection after three days of training. In order to ensure the quality of the data collected, all survey forms were centralized and examined at the end of the day, and corrections were made after the checks.

Data were analyzed using Stata ${ }^{\circledR}$ software version 13 . The descriptive part of the analysis consisted of calculating parameters of central tendency (median or mean) and dispersion (standard deviation) for quantitative variables. Relative frequencies were calculated for qualitative variables. To identify determinants of delay in HCUMT in children under five, a two-step approach was used. A bivariate analysis was performed first using the simple logistic regression by crossing the dependent variable with the independent variables, followed by a multivariate analysis using a logistic regression and the stepwise digressive method. All statistically significant variables at $\mathrm{p}<0.20$ in the bivariate analysis were included in the initial multivariate model. Hosmer-Lemeshow test was performed to assess the adequacy of the model. The significant level of selected variables in the final model was set at $\mathrm{p}<0.05$. To identify the potential confounding variables, a crossover of the associated independent variables was performed. The data were weighted taking into account the probability of inclusion of the study mothers or caregivers [14].

\subsection{Ethical Considerations}

The objectives of the study were explained to the participants. Voluntary informed oral consent was obtained from each mother before starting the interview. The consent claimed that the participants were not at risk by refusing to participate in the survey or stopping their collaboration during the study and would not have their malaria treatment care impacted in any way prior to commencing the interview. The confidentiality and anonymity of the information collected were respected. We obtained the approval of local authorities of Ouidah municipality before the investigation started.

\section{Results}

\subsection{Study Design and Sampling}

482 mother-child pairs were included in this study. The 
median age of children (Table 1) was 2 years [1 year; 3 years] and the majority of children were one year old. The sex ratio was 1.2 boys for one girl. Most of the children (94.5\%) were living with their biological mothers, while $5.5 \%$ were under their grandmothers' supervision and $22.4 \%$ have been hospitalized at least once in the past.

Among mothers or babysitters (Table 2), the mean age was $29.5 \pm 7.4$ years. Half of the mothers were in the 26 to 35 year of age group, $5.7 \%$ were with no schooling and $54.2 \%$ were housewives. More than half (52\%) lived within $5 \mathrm{~km}$ from a local health facility, 62.0\% used the motorcycle as a means of travel to the health facility, compared to $36.7 \%$ who traveled on foot.

\subsection{Knowledge of Mothers about Malaria}

Mothers or babysitters, who were able to identify important symptoms of simple malaria (Table 3), such as fever, were $91.5 \%$. Only $0.83 \%$ who could consider plasmodium as the direct cause of malaria. Some erroneous ideas like the role of the sun and food (groundnut) still persist in $90 \%$ of them, while $47 \%$ considered the consumption of improper water as the major cause of the disease. As a means of preventing malaria, the use of (Long Lasting Insecticidal Net) LLIN was regarded by $98.8 \%$ of the mothers or babysitters. Regarding curative treatment, $64.5 \%$ had referred to consultation in a health facility as the best possibility for malaria treatment. On the other hand, $28.2 \%$ used medicinal plants and $6.8 \%$ of the mothers or caregivers of children investigated mentioned self-medication. Two (2) mothers or babysitters used prayer as a means of treatment. In total, $46.7 \%$ of mothers had an average level of knowledge of malaria compared with $11.8 \%$ who showed a low level of awareness.

Table 1. Delays in HCUMT in children under five in Benin southern setting according to the characteristics of children, Ouidah, June 2017

\begin{tabular}{|c|c|c|c|c|}
\hline \multirow{2}{*}{\multicolumn{2}{|c|}{ Variables }} & \multicolumn{2}{|c|}{ Delays in health care utilization } & \multirow{3}{*}{$\begin{array}{c}\text { p-value } \\
0.0000\end{array}$} \\
\hline & & \multirow{2}{*}{$\begin{array}{c}\text { Yes n (\%) } \\
97(85.8)\end{array}$} & \multirow{2}{*}{$\frac{\text { No n (\%) }}{16(14.2)}$} & \\
\hline Age (years) & $<1$ & & & \\
\hline & $1-2$ & 172 (81.9) & 38 (18.1) & \\
\hline & $3-4$ & $136(85.5)$ & $23(14.5)$ & \\
\hline \multirow{2}{*}{ Sex } & Male & $215(82.1)$ & 47 (17.9) & 0.20 \\
\hline & Female & $190(86.4)$ & $30(13.6)$ & \\
\hline \multirow{3}{*}{ Number of child in the household } & 1 & $219(83.6)$ & $43(16.4)$ & 0.30 \\
\hline & 2 & $157(85.3)$ & $27(14.7)$ & \\
\hline & $\geq 3$ & $29(82.9)$ & $6(17.1)$ & \\
\hline \multirow[t]{2}{*}{ Kinship with respondent } & Mother & $383(84.2)$ & $72(15.8)$ & 0.71 \\
\hline & Grand-mother & $22(81.5)$ & $5(18.5)$ & \\
\hline \multirow[t]{2}{*}{ History of past hospitalization } & Yes & 85 (78.7) & $23(21.3)$ & 0.087 \\
\hline & No & $320(85.6)$ & $54(14.4)$ & \\
\hline \multirow[t]{2}{*}{ Anti-measles immunization } & Yes & $246(83.7)$ & $48(16.3)$ & 0.83 \\
\hline & No & $62(82.7)$ & $13(17.3)$ & \\
\hline \multirow[t]{2}{*}{ Immunization against tuberculosis } & Yes & $390(84.4)$ & $72(15.6)$ & 0.26 \\
\hline & No & $15(75.0)$ & $5(25.0)$ & \\
\hline \multirow[t]{2}{*}{ Using of long-lasting insecticide-treated nets } & Yes & $377(84.3)$ & $70(15.7)$ & 0.49 \\
\hline & No & $28(80)$ & $7(20)$ & \\
\hline
\end{tabular}


Determinants of Delays in Health Care Utilization for Malaria

Treatment (HCUMT) in Children under Five in Benin Southern Setting

Table 2. Delays in HCUMT in children under five in Benin southern setting according to the characteristics of mothers, Ouidah, June 2017

\begin{tabular}{|c|c|c|c|}
\hline \multirow{2}{*}{ Variables } & \multicolumn{2}{|c|}{ Delays in health care utilization } & \multirow{2}{*}{ p-value } \\
\hline & Yes n (\%) & No n (\%) & \\
\hline \multicolumn{4}{|l|}{ Age (years) } \\
\hline$\leq 25$ & $135(84.4)$ & $25(15.6)$ & 0.82 \\
\hline 26-35 & $203(84.6)$ & $37(15.4)$ & \\
\hline$\geq 36$ & 67 (81.7) & $15(18.3)$ & \\
\hline \multicolumn{4}{|l|}{ Occupation } \\
\hline Formal sector employee & $54(84.4)$ & $10(15.6)$ & 0.85 \\
\hline Informal sector employee & $134(82.7)$ & $28(17.3)$ & \\
\hline Trader & $217(84.8)$ & $39(15.2)$ & \\
\hline \multicolumn{4}{|l|}{ Education } \\
\hline No schooling & $141(82.0)$ & $31(18.0)$ & 0.65 \\
\hline Primary & $163(85.3)$ & $28(14.7)$ & \\
\hline High/University & $101(84.9)$ & $18(15.1)$ & \\
\hline \multicolumn{4}{|l|}{ Marital status } \\
\hline Married & $325(86.0)$ & $53(14.0)$ & 0.026 \\
\hline Non married & $80(76.9)$ & $24(23.1)$ & \\
\hline \multicolumn{4}{|l|}{ Religion } \\
\hline Christianism & $311(84.3)$ & $58(15.7)$ & 0.89 \\
\hline Endogen religion & $76(82.6)$ & $16(17.4)$ & \\
\hline Islam & $18(85.7)$ & $3(14.3)$ & \\
\hline \multicolumn{4}{|l|}{ History of child death } \\
\hline Yes & $89(84.0)$ & $17(16.0)$ & 0.98 \\
\hline No & $316(84.0)$ & $60(16.0)$ & \\
\hline \multicolumn{4}{|l|}{ Distance to health care facility } \\
\hline$\leq 5 \mathrm{~km}$ & $209(85.0)$ & $37(15.0)$ & 0.57 \\
\hline$>5 \mathrm{~km}$ & $196(83.1)$ & $40(16.9)$ & \\
\hline \multicolumn{4}{|l|}{ Transportation mean } \\
\hline Foot & $156(91.2)$ & 15 (8.8) & 0.0055 \\
\hline Moto & 243 (79.9) & $61(20.1)$ & \\
\hline Vehicle & $6(85.7)$ & $1(14.3)$ & \\
\hline \multicolumn{4}{|l|}{ Transportation cost } \\
\hline Not expensive & 205 (87.6) & $29(12.4)$ & 0.00016 \\
\hline Expensive & $124(74.3)$ & $43(25.7)$ & \\
\hline Very expensive & 56 (93.3) & $4(6.7)$ & \\
\hline
\end{tabular}


Table 3. Prevalence of delays in HCUMT in children under five according to mothers' perceptions on malaria Ouidah, June 2017

\begin{tabular}{|c|c|c|c|}
\hline \multirow{2}{*}{ Variable } & \multicolumn{2}{|c|}{ Delays in health care utilization } & \multirow{2}{*}{ p-value } \\
\hline & Yes n (\%) & No (\%) & \\
\hline \multicolumn{4}{|c|}{ Malaria severity for a child under five } \\
\hline Ordinary sickness & $226(85.6)$ & $38(14.4)$ & 0.57 \\
\hline Serious illness & $122(82.4)$ & $26(17.6)$ & \\
\hline Very serious illness & $57(81.4)$ & $13(18.6)$ & \\
\hline \multicolumn{4}{|c|}{ Effectiveness of treatment at the Health Center } \\
\hline Not effective & $22(84.6)$ & $4(15.4)$ & 0.18 \\
\hline Effective & $356(83.2)$ & $72(16.8)$ & \\
\hline Highly effective & $27(96.4)$ & $1(3.6)$ & \\
\hline \multicolumn{4}{|c|}{ Trust in the treatment given at the health Center } \\
\hline Yes & 395 (83.9) & $76(16.1)$ & 0.53 \\
\hline No & $10(90.9)$ & $1(9.1)$ & \\
\hline \multicolumn{4}{|c|}{ Trust at the Health Center } \\
\hline Not confident & $23(95.8)$ & $1(4.2)$ & 0.037 \\
\hline Confident & $346(82.4)$ & $74(17.6)$ & \\
\hline Very confident & $36(94.7)$ & $2(5.3)$ & \\
\hline \multicolumn{4}{|c|}{ Shortage of antimalarial drugs } \\
\hline Yes & $90(86.5)$ & $14(13.5)$ & 0.43 \\
\hline No & $315(83.3)$ & $63(16.7)$ & \\
\hline \multicolumn{4}{|c|}{ Shortage in Rapid diagnosis test } \\
\hline Yes & $18(94.7)$ & $1(5.3)$ & 0.19 \\
\hline No & $387(83.6)$ & $76(16.4)$ & \\
\hline \multicolumn{4}{|c|}{ Waiting time at health center } \\
\hline Not long & $204(85.0)$ & $36(15.0)$ & 0.81 \\
\hline Long enough & $163(82.7)$ & $34(17.3)$ & \\
\hline Very long & $38(84.4)$ & $7(15.6)$ & \\
\hline \multicolumn{4}{|c|}{ Reception at the Health Center } \\
\hline Bad & $33(82.5)$ & $7(17.5)$ & 0.23 \\
\hline Good & 357 (83.6) & $70(16.4)$ & \\
\hline Very good & $15(100.0)$ & $0(0.0)$ & \\
\hline \multicolumn{4}{|c|}{ Cost of malaria treatment at the Health Center } \\
\hline Not expensive & $153(82.7)$ & $32(17.3)$ & 0.41 \\
\hline Expensive & $214(85.9)$ & $35(14.1)$ & \\
\hline Very expensive & $38(79.2)$ & $10(20.8)$ & \\
\hline \multicolumn{4}{|c|}{ Communication between health workers and patients } \\
\hline Yes & $388(83.8)$ & $75(16.2)$ & 0.51 \\
\hline No & $17(89.5)$ & $2(10.5)$ & \\
\hline \multicolumn{4}{|c|}{ Belief in malaria prevention } \\
\hline Yes & $339(86.0)$ & $55(14.0)$ & 0.011 \\
\hline No & $66(75.0)$ & $22(25.0)$ & \\
\hline
\end{tabular}




\subsection{Perceptions of Malaria and Its Management in Municipal Health Facilities}

Malaria in a child under five years of age was considered to be of trivial gravity by $53.7 \%$ of the investigated mothers or caregivers (Table 3); while $32.4 \%$ found it as a serious disease. In terms of care in a health facility, almost all respondents (97.6\%) trusted the treatment provided; and $88.6 \%$ found the treatment to be effective as compared to $5.8 \%$ who considered it ineffective. The waiting time in the health facilities appeared to be quite long for $42.9 \%$, but they felt that hospitality was adequate in $88.1 \%$ of cases. Among mothers, $52.7 \%$ found the cost of malaria treatment expensive in the area, but $82.2 \%$ felt it was possible to prevent malaria.

\subsection{Characteristics of the Social Environment}

In Ouidah, $58.0 \%$ of households consisted of 4 to 6 members, and $34.0 \%$ of households preferred self-medication to treat malaria in their infants under 5 years of age versus $11.8 \%$ who used medicinal leaves (Table 4). However, in $80.3 \%$ of the cases, it was fathers who decided the type of treatment and only $16.5 \%$ of the mothers could decide

Table 4. Prevalence of delays in HCUMT in children under five according to mother social environment Ouidah, June 2017

\begin{tabular}{|c|c|c|c|}
\hline \multirow{2}{*}{ Variable } & \multicolumn{2}{|c|}{ Delays in health care utilization } & \multirow{2}{*}{ p-value } \\
\hline & Yes n (\%) & No (\%) & \\
\hline \multicolumn{4}{|l|}{ Number of household members } \\
\hline$\leq 3$ & $53(82.8)$ & $11(17.2)$ & 0.30 \\
\hline $4-6$ & $243(85.9)$ & $40(14.1)$ & \\
\hline$\geq 7$ & $109(80.7)$ & $26(19.3)$ & \\
\hline \multicolumn{4}{|c|}{ Preferred mode of treatment in the household } \\
\hline Home treatment & $137(89.5)$ & $16(10.5)$ & 0.077 \\
\hline Use of medicinal plants & $50(80.6)$ & $12(19.4)$ & \\
\hline Treatment at the hospital & $218(81.6)$ & $49(8.4)$ & \\
\hline \multicolumn{4}{|c|}{ Responsible for the treatment decision in the household } \\
\hline Husband & $316(83.6)$ & $62(16.4)$ & 0.33 \\
\hline Self & $78(87.6)$ & $11(12.4)$ & \\
\hline Grand parent & $11(73.3)$ & $4(26.7)$ & \\
\hline \multicolumn{4}{|c|}{ Prayer practice for treatment within the household } \\
\hline Yes & $93(86.9)$ & $14(13.1)$ & 0.35 \\
\hline No & $312(83.2)$ & $63(16.8)$ & \\
\hline \multicolumn{4}{|c|}{ Knowledge of malaria awareness campaign activities } \\
\hline Yes & $395(85.3)$ & $68(14.7)$ & 0.0001 \\
\hline No & $10(52.6)$ & $9(47.4)$ & \\
\hline \multicolumn{4}{|c|}{ Participation in an awareness activity on malaria } \\
\hline Yes & $299(86.7)$ & $46(13.3)$ & 0.012 \\
\hline No & $106(77.4)$ & $31(22.6)$ & \\
\hline \multicolumn{4}{|c|}{ Knowledge about CHW activities } \\
\hline Yes & $38(84.0)$ & $73(16.0)$ & 0.0000 \\
\hline No & $21(84.0)$ & $4(16.0)$ & \\
\hline \multicolumn{4}{|l|}{ Participation in CHW activities } \\
\hline Yes & $140(83.3)$ & $28(16.7)$ & 0.76 \\
\hline No & $265(84.4)$ & $49(15.6)$ & \\
\hline \multicolumn{4}{|c|}{ Appreciation of the usefulness of $\mathrm{CHW}$} \\
\hline Not useful & $24(82.8)$ & $5(17.2)$ & 0.23 \\
\hline Useful & $335(83.1)$ & $68(16.9)$ & \\
\hline Very useful & $46(92.0)$ & $4(8.0)$ & \\
\hline \multicolumn{4}{|c|}{ CHW: Community Health Workers } \\
\hline
\end{tabular}




\subsection{Characteristics of Malaria}

The main characteristic of malaria was fever. The mode of onset of the disease was progressive in $51 \%$ of the children against $49 \%$ of abrupt onset. The two predominant symptoms were shivering and lack of appetite, according to $32 \%$ of the mothers or babysitters, while $16.6 \%$ reported an association of the three symptoms: chills, lack of appetite and crying.

\subsection{Delay between the Onset of Fever and Health Facilities Utilization}

Of the 482 children under five years of age, 423 were referred to the health facilities for more than 24 hours after the onset of fever. The prevalence of delayed utilization of health facilities for malaria management in children under 5 years was $87.8 \%$ (95\% CI: $81.6 \%$ - 92.8). Of these, $68.5 \%$ accessed health facility after 72 hours of onset of fever, 13.6\% between 25 and 48 hours and 12.2\% within 24 hours. The prevalence of delayed utilization of health facilities for malaria management in children under 5 years did not change significantly according to the level of knowledge of mothers of children on malaria. These rates of prevalence were $83.1 \%$ among mothers with a low level of knowledge, $80.1 \%$ among mothers with a medium level of knowledge, and $89.3 \%$ of those with a high level of knowledge about malaria.

\subsection{Determinants of Delays in HCUMT in Children}

Results of the multivariate analysis from a logistic regression adjusted for confounders (Table 5) showed that the delays in HCUMT in children under five varied depending on whether mothers were married ( $\mathrm{OR}=4.4,95 \%$ CI: 2.2-8.8), they used motorcycle as a means of travel to health facilities (OR $=2.3,95 \%$ CI: 1.1-5.2), complained about the high cost of transport (OR $=2.4,95 \% \mathrm{CI}$ 1.2-4.7), or believed in the possibility of preventing malaria (OR $=2.4,95 \%$ CI: $1.2-4.7)$. When care costs are paid by both the parents or by the grandparents at the same time, then children were less likely to have late recourse $(\mathrm{OR}=0.4,95 \% \mathrm{CI}: 0.2-0.7)$ compared to when only the mother or only the father had paid the treatment fee.

Table 5. Multivariate analysis by logistic regression. Determinants of delays in HCUMT in children under five, Ouidah, June 2017

\begin{tabular}{|c|c|c|}
\hline Variable & Odds Ratio (C.I. 95\%) & p-value \\
\hline \multicolumn{3}{|l|}{ Marital status } \\
\hline Free union & 1.0 & \\
\hline Married & $4.4(2.2-8.8)$ & 0.0000 \\
\hline \multicolumn{3}{|c|}{ Transportation mean to health center } \\
\hline Foot & 1.0 & \\
\hline Moto & $2.3(1.1-5.2)$ & 0.0359 \\
\hline Vehicle & $2.2(0.2-23.2)$ & 0.5259 \\
\hline \multicolumn{3}{|l|}{ Transportation cost } \\
\hline Not expensive & 1.0 & \\
\hline Expensive & $2.4(1.2-4.7)$ & 0.0129 \\
\hline Very expensive & $0.6(0.2-1.9)$ & 0.3574 \\
\hline \multicolumn{3}{|l|}{ Belief in malaria prevention } \\
\hline Yes & 1.0 & \\
\hline No & $2.4(1.2-4.7)$ & 0.0134 \\
\hline \multicolumn{3}{|c|}{ Responsible for payment of processing fees } \\
\hline Mother only & 1.0 & \\
\hline Father only & $0.8(0.4-1.5)$ & 0.464 \\
\hline Grand parent & $0.1(0.0-0.6)$ & 0.0108 \\
\hline Mother and Father together & $0.4(0.2-0.7)$ & 0.0042 \\
\hline \multicolumn{3}{|c|}{ Participation in an awareness activity on malaria } \\
\hline Yes & 1.0 & \\
\hline No & $2.8(1.4-5.5)$ & 0.0024 \\
\hline \multicolumn{3}{|l|}{ Onset mode of the disease } \\
\hline Sudden & 1.0 & \\
\hline Progressive & $2.1(1.2-3.9)$ & 0.0152 \\
\hline \multicolumn{3}{|l|}{ Comorbidities associated } \\
\hline No & 1.0 & \\
\hline Yes & $2.2(1.1-4.1)$ & 0.0177 \\
\hline \multicolumn{3}{|c|}{ Test de Hosmer-Lemeshow: $\mathrm{p}=0.64$} \\
\hline
\end{tabular}




\section{Discussion}

The study examined the determinants of delays in HCUMT in children under five in Benin southern setting. Delays in HCUMT in children under five are associated with the marital status of mothers, the transportation means to health facilities, the belief in the possibility of preventing malaria, and the family member who pay health care fees.

\subsection{Prevalence of Delays in HCUMT in Children}

In line with health policy recommendations for better management of cases of fever in children under five years of age $[15,16]$, only $12.2 \%$ of mothers or babysitters consulted in a health facility in less than 24 hours of the onset of fever. It is therefore estimated that few children benefit from early and effective treatment against simple malaria, which could evolve into a life-threatening or even fatal disease [17]. The prevalence observed in our study is comparable to that of $87.8 \%$ reported by Dida et al (2015) in Ethiopia [18]. On the other hand, some results obtained in other African countries have shown the average prevalence of delay in health care utilization, as in Uganda (55.2\%), Tanzania (55.4\%), and Nigeria (51.5\%) [19-21]. These results show that the delay in the provision of malaria treatment to health facilities is high in the communities of sub-Saharan Africa. This would be justified by the fact that the majority of mothers initially self-medicate before seeking health care [22].

\subsection{Therapeutic Itinerary}

The main types of uses by mothers and babysitters for malaria treatment in children less than five years of age were self-medication, use of medicinal plants and consultation in a health facility. A study in Kenya showed that the types of remedies used to treat malaria are similar in most African countries [8]. The practice of home care is very common, as in Senegal, where the results of a survey revealed that $91.1 \%$ of children suffering from malaria receive self-medication before resorting to an external source. As confirmed by our findings, a multi-center study in six countries in sub-Saharan Africa, including Benin, revealed the multiple sources of malaria treatment among children under five [17-23]. 4.3. Determinants of delays in HCUMT in children

The results of the multivariate analysis identified the factors associated with late treatment for malaria in children less than five years. Children whose mothers were married were four times more likely to be late in consultation in a health facility as compared to the children whose mothers were living with common-law mothers. It is assumed that these married women are most often obliged to obtain permission from their husbands before driving their sick children to a health facility. The financial dependence of women in sub-Saharan Africa may lead the latter to wait until the husband pays the costs of consultation and travel to go to a health facility. The role of monogamous marriage in the late treatment of malaria in our study, where $78 \%$ of the married mothers or babysitters were concerned, was reported by other results in Africa [24].

It was also found that mothers or babysitters who used motorcycles as a means of transportation to health facilities were 2.3 times more likely to experience delayed management of malaria in children under five than those traveling on foot or by any other means. This was because families feel they can reach the health center in a short time by using their motorcycles. With regard to the distance between the homes and the health facilities, it was implicated elsewhere as a factor favoring late recourse [13, 20-24]. However, it has not been identified as such in our results. It is believed to be related to the fact that some mothers or babysitters did not have the ability to accurately estimate a distance. In our study, the cost of transportation is a measure of distance; since it is set according to the distance to be traveled. The longer the distance to go in a health facility, the more expensive (or high) will be the cost of transportation. Yet the low cost of transport for some mothers or babysitters increased by 2.4 times the risk of late recourse to health facilities than among those who did not complain. The high cost of transport is reported in several studies as a factor favoring late recourse to health facilities [25]. On the basis of this reality, a high cost of transport could be a limiting factor in the early use of health facilities and should favor rather a late recourse by the fact that mothers should wait until they have the necessary resources.

Mothers or babysitters who believed in the possibility of preventing malaria were twice as likely to resort to late health care as those who did not. This is due to the effect of certain knowledge and perceptions that some mothers or caregivers have of malaria. However, although some authors cited the level of knowledge as a factor favoring late recourse [26], it was not identified as an associated factor in this study. Knowledge neither constitutes perception nor practice, let alone behavior [13].

Participation in an awareness-raising activity on malaria was 2.8 times more important for mothers to resort late to health facilities than their pairs who had never participated in such activity. Logically, participation in desensitization activities on malaria is thought to promote better behavior. Since the change in behavior is a lengthy process, mothers would certainly not have participated in more awareness sessions and on an ongoing basis to achieve good behavior. Children with comorbidity were 2.2 times more likely to have delayed treatment for malaria than children with malaria. A sneaky start of any disease does not often cause fear, especially when it comes to children who are not able to express their suffering. One would think of a minor or passenger problem, which would not require a 
rapid recourse to a health facility. This means that the most contemplated solutions include self-medication, and the use of medicinal plants for example [10]. When both the parents or the grandparents pay health care costs at the same time, then the children were less likely to have recourse or the late recourse than when the mother alone or the lone parent paid the treatment. The payment of care costs by both parents was seen as a sign of harmony and cohesion in the household and could be a protective factor that would promote early treatment for the treatment of sick children.

\section{Conclusions}

The prevalence of delays in HCUMT in children less than five years is high in Ouidah in Benin south setting.

Organization of simple malaria management through community training, regular and continuous supply of inputs (medicines and diagnosis tests) for malaria control, and elevating socioeconomic status of community members of Ouidah would significantly reduce the very high prevalence of delays in HCUMT in children under five years.

\section{Acknowledgements}

We are very grateful to experts for their appropriate and constructive suggestions to improve this template. The authors thank the study participants, the data collectors and health workers involved in the study.

\section{Competing Interests}

The authors declare that they have no competing interests.

\section{REFERENCES}

[1] Ministère de la Santé (MS). Annuaire des statistiques sanitaires 2015. Bénin: Ministère de la Santé; 2015.

[2] World Health Organization (WHO). World malaria report 2016 [Internet]. World Health Organization; 2016 [cité 20 mai 2017]. Disponible sur: http://www.who.int/malaria/pub lications/world-malaria-report-2016/report/en/

[3] Herrera S, Ivanovich E, Yé Y, Garley A. Suivi et évaluation des programmes de lutte contre le paludisme [Internet]. [cité 20 mai 2017]. Disponible sur: https://www.measureevaluati on.org/resources/publications/ms-16-110-fr/at download/document

[4] World Health Organization (WHO). Achieving the malaria MDG target: reversing the incidence of malaria 2000-2015 [Internet]. World Health Organization and the United
Nations Children's Fund; 2015 [cité 20 mai 2017]. Disponible sur: http://www.who.int/malaria/publications/at oz/9789241509442/en/

[5] Programme National de Lutte Paludisme (PNLP). Plan stratégique national (2014-2018). Bénin: Programme national de lutte contre le paludisme; 2016.

[6] Ministère de la Santé (MS). Organisation du système de santé. MS-Observatoire des ressources humaines en santé du Bénin [Internet]. 2013 [cité 20 mai 2017]. Disponible sur: http://www.sante.gouv.bj/observatoire-rhs/spip.php?article

[7] Zone Ouidah/Kpomassè/Tori-Bossito. Annuaire des statistiques sanitaires 2015 de la zone Ouidah/Kpomassè/Tori-Bossito. Bénin: Zone sanitaire Ouidah/Kpomassè/Tori-Bossito; 2015.

[8] Chuma J, Okungu V, Molyneux C. Barriers to prompt and effective malaria treatment among the poorest population in Kenya. Malar J. 2010; (9):144-53.

[9] Deressa W, Ali A, Enqusellassie F. Self-treatment of malaria in rural communities, Butajira, southern Ethiopia. Bull World Health Organ. 2003;81 (4):261-8.

[10] Chibwana A.I, P Mathanga D, Chinkhumba J, Campbell C.H. Socio-cultural predictors of health-seeking behaviour for febrile under-five children in Mwanza-Neno district, Malawi. Malar J. 2009; (8):219-26.

[11] Silweya D, Baboo K.S et al. Barriers to Prompt Malaria Treatment among Under Five Children in Mpika District. Med J Zambia. 2013;(40 (4)):121-5.

[12] Kaputu-Kalala-Malu C, Mukeba Kahamba D, Ntumba-Tshitenge O, Mafuta Musalu E, Ndahindwa V, Okitundu Luwa D. Convulsions prolongées chez l'enfant en Afrique Subsaharienne. Aspects cliniques et prise en charge. Médecine Santé Trop. 2015; (25):306-11.

[13] Xu JW, Xu QZ, Liu H, Zeng YR. Malaria treatment-seeking behaviour and related factors of Wa ethnic minority in Myanmar: a cross-sectional study. Malar J. 2012; (11):41723.

[14] Lemeshow S, Robinson D. Survey to measure programme coverage and impact: a review of the methodology used by Expanded Programme on Immunization. World Health Stat Q. 1985; (38):65-75.

[15] Roll Back Malaria (RBM). The global malaria action plan. Roll Back Malaria 2005 -2015 [Internet]. Roll Back Malaria Partnership - Geneva; 2015 [cité 20 mai 2017]. Disponible sur: : http://archiverbm.rollbackmalaria.org/gmap/gmap.pdf

[16] World Health Organization (WHO). The Roll Back Malaria strategy for improving access to treatment through home management of malaria [Internet]. Geneva: World Health Organization; 2005 [cité 20 mai 2017]. Disponible sur: http://apps.who.int/iris/bitstream/10665/69057/1/WHO_HT M_MAL_2005.1101.pdf

[17] Chuma J, Abuya T, Memusi D, Juma E, Akhwale W, Ntwiga J. Reviewing the literature on access to prompt and effective malaria treatment in Kenya: implications for meeting the Abuja targets. Malar J. 2009; (8):243-9.

[18] Dida N, Darega B and Abebe A. Treatment Seeking Behavior and Associated Factors Among Malaria Suspected Patients in Bale Zone, Southeast Ethiopia: Institution-Based 
Cross-sectional Study. J Fam Med. 2009;2 (1):5.

[19] Rutebemberwa E, Kallander K, Tomson G, Peterson S, Pariyo G. Determinants of delay in care-seeking for febrile children in eastern Uganda. Trop Med Int Health. 2009;14(4):472-9.

[20] Kassile T, Lokina R, Mujinja P, Mmbando BP. Determinants of delay in care seeking among children under five with fever in Dodoma region, central Tanzania: a cross-sectional study. Malar J. 2014; (13):348-54.

[21] Chukwuocha U M, Okpanma A C, Nwakwuo G C, Dozie Ikechukwu N S. Determinants of Delay in Seeking Malaria Treatment for Children Under-Five Years in Parts of South Eastern Nigeria. J Community Health. 2014;(39):1171-8.

[22] Franckel A, Arcens F, Lalou R,. Contexte villageois et recours aux soins dans la région de Fatick au Sénégal. Population. 2008;63(3):531-53.

[23] Littrell M, Gatakaa H, Evance I, et al. Monitoring fever treatment behaviour and equitable access to effective medicines in the context of initiatives to improve ACT access: baseline results and implications for programming in six African countries. Malar J. 2011; (10):327.

[24] Romay-Barja M, Cano J, Ncogo P, et al. Determinants of delay in malaria care-seeking behaviour for children 15 years and under in Bata district, Equatorial Guinea. Malar J. 2016; (15):187.

[25] Getahun et al. Determinants of delay in malaria treatment-seeking behaviour for under-five children in south-west Ethiopia: a case control study. Malar J. 2010; (9):320.

[26] Tipke M, Louis RV, Yé M, et al. Access to malaria treatment in young children of rural Burkina Faso. Malar J. 2009; (8):266. 